\title{
Presentation and Quality Evaluation of a Novel Learning Method for Pharmacy Students in Drug Information Course
}

\author{
Kaveh Eslami", Leila Kouti, Maryam Aghakouchakzadeh, Mina Khezrian, Mandana Izadpanah
}

Department of Clinical Pharmacy, School of Pharmacy, Ahvaz Jundishapur University of Medical Sciences, Ahvaz, IRAN.

\begin{abstract}
Introduction: Personal computers or laptops and smartphones has been used to change the lecture based traditional class to an interactive workshop to educate the knowledge and skills necessary for using drug information resources in clerkship courses. Methods: After the needs assessment and educational facilities, the appropriate drug information questions corresponding to each source were designed. Students used their laptops and smartphones to find the answer to drug information questions. The OSCE exam was taken at the end of the course to evaluate the skills obtained by the students. The scores of knowledge exam and OSCE skills exam of this group were compared with students of the previous period. The data were analyzed by descriptive and inferential statistic, Paired t-Test, and Pearson Correlation. Results: The mean scores of the knowledge exam compare to prior group increased significantly $(6.79 \pm 0.78$ in group I, $9.96 \pm 0.91$ in Group II, P-value<0.01). Moreover, the OSCE exam scores (6.15 \pm 0.88$)$ improved significantly ( $\mathrm{P}$-value $<0.05)$ in comparison to the scores of the previous traditional lecture-based classes (4.97 \pm 0.73 ). Conclusion: Our method to train drug information resources by the using of laptop and smartphones could be an appropriate method to improve the quality of education, students' knowledge, and skills.
\end{abstract}

Key words: Drug information education resources, Laptop, Smart phone, Pharmacy, clerkship course.

\section{BACKGROUND}

One of the important roles of the pharmacist is responding to the questions from patients and medical staff. For this purpose, education of drug information is one of the main parts of pharmacy education. The drug information very broad topic of debate in medical science that is changing remarkably quickly. Therefore, the training program of drug information sources and methods to achieve an appropriate response are necessary for pharmacy students. This education may help students to find proper information. It seems utilization of electronic resources could be an effective way to educate drug information. ${ }^{1,2}$ Most available electronic resources of drug information are computer software and the applications which designed for smartphones and perform online and offline.

On the other hand, Medical science has experienced rapid changes in recent years. Nowadays, medical science teachers have found traditional methods of teaching are insufficient for medical science education. ${ }^{3,4}$ There is a growing concern among medical educators that conventional methods of teaching (lecture-based curricula) are not linked to the complexity of medical science and new technologies including access to the information via the internet. ${ }^{5}$ According to several studies, lecturing is the main teaching method used in universities, but this type of education associated with disadvantages including the passive role of students and the little account of this
Submission Date: 09-10-2017; Revision Date: 05-12-2017; Accepted Date: 17-05-2018

DOI: 10.5530/ijper.52.4.66 Correspondence: Dr Kaveh Eslami, Department of Clinical Pharmacy, School of Pharmacy, Ahvaz Jundishapur University of Medical Sciences, Ahvaz, IRAN. Phone no: 0098-9123118304 E-mail: drkaveheslami@ gmail.com

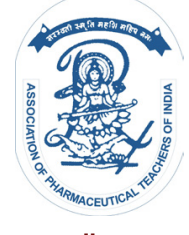

www.ijper.org 
contemporary thinking. ${ }^{6,7}$ Alteration of education methods toward compatibility with the increasing of progression of science has been considered in developed countries. One of these methods is interactive lectures and problem base learning which can be performed in small-group discussions about medical cases. ${ }^{8}$

In several countries, training is conducted by electronic methods, the progression of this method is lower in Iran. ${ }^{9}$ Despite technological advancements, electronic devices as laptops and smartphones have not been applied in medical education in Iran. But it seems that the use of this equipment is one of the best methods for encouraging students to participate interactively in the classroom. ${ }^{10}$

Therefore, the present study was designed to assess the using of smartphones and laptop computers to change the lecture-based traditional class to an interactive class to educate the knowledge and the skills necessary for using drug information resources.

\section{Procedure}

This study was a cross-Sectional and interventional, which held a drug information resources session of clerkship courses of the hospital for the 5th academic year of pharmacy students of Ahwaz University of medical sciences in 1392 and 1393. The drug information resources session presented lecture-based plus immediately practical classes in the University Computer Center, which is nominated group I with 46 participants in 1392. Other session held in 1393 and interactive workshop presented for 44 students as group II.

\section{Needs assessment}

The students were spent drug information resources courses were carried out the survey about education needs and quality of satisfaction. Education methods for prior students include lecture alone and the other group education method was lecture plus immediately practical classes in the university Computer Center (Group I). Also, need assessment of the four professors of Clinical Pharmacy department of the school of pharmacy shown interactive and practical educations of drug information resources are necessary for students.

\section{Design of need assessment and satisfaction questionnaire}

The need assessment questionnaires for students and professors include 4 and 3 questions, respectively. Satisfaction questionnaire had 8 questions. These questionnaires were valid by Content validity ratio (CVR) and Content validity index (CVI) using a sample consist of 15 randomly selected professors. The relevance of questions evaluated by calculation of CVR, CVR members include "essential," "useful, but not essential," or "not necessary". CVI Members of were asked to rate each item that was "relevancy", "clarity", and "simplicity. ${ }^{11}$ Also, the reliability of questionnaire calculated, 40 students selected randomly was spent drug information resources courses and they respond the need assessment and satisfaction questionnaire at two different times with two-week intervals. 4 professors completed the need assessment questionnaire for measuring reliability under the same conditions. Cronbach's alpha was used for assessing the internal consistency reliability. ${ }^{12}$

\section{Selection of drug information resources}

The selection of drug information resources was carried out based on the needs assessment of 4 clinical pharmacy professors. Update and authoritative source of drug information in book format, pharmaceutical applications, and websites and smartphone applications were considered. The aim of these selections was to familiarize students with the correct way of using and application of each of the resources to access drug information.

\section{Planning and designing the suitable problem relating to the drug information resources}

Planning was performed based on the topics assigned to the education of the students. Based on pharmacy education curriculum, the topic of application of drug information resources has been predicted in hospital pharmacy clerkship course, therefore the training sessions of this course were chosen for this assessment. The drug information questions corresponding to each source were designed for the students. The students were asked to be present in the classroom of clerkship course at next sessions with a laptop and smartphone containing drug information applications (Drug information apps was given to students). Four sessions were considered in the training program including the content of history, need for using and applying the drug information resources, how to answer questions about drug information, introducing reference books in first session, answering questions using Up-to-date drug information software in second session, answering drug information questions using websites in third session and finally answering drug information questions using pharmaceutical apps of smartphones at the end of session.

Then, the questions which have been designed to use different sections of each resource were given to students. Students used their laptop and smartphone by supervision of two instructors to find the correct answer to the designed question. Students could use the laptop, smartphone or both to find the answer. In addition, students had access to the internet through the wireless network 
of the faculty of Pharmacy to provide the taking of advantage of web-based drug information resources.

At the end of the fourth session, the acquired knowledge by students is evaluated through the designed tests based on the course contents and the results were compared with the previous groups (first group). Also, students were asked about their satisfaction with new methods for presenting of drug information resources. In order to assess the knowledge and skills resulted in two methods, skill exam of OSCE (Objective Structured Clinical Examination) at the end of each period was used. At the end of the period, scores of knowledge exam and OSCE skills exam of this group were compared with students of the previous period using statistical analysis, which was done by SPSS V.19 by means of T-tests. Means of scores, significant differences (by p-value $<0.05)$ and percent of answers were analyzed.

\section{RESULTS}

\section{The results of the needs assessment}

Assessment of results described $78.5 \%$ percent of students in the lecture alone group (33 of 42) stated that presenting of drug information resources as lecture very low and low resolve students'practical needs and will not produce the necessary skills to use drug information resources. In addition, 65 percent of students (30 of 46 patients) of the second period (first group) who passed practical workshops with an interval after class lectures expressed that attended classes are inadequate for the training of this skill. 82 percent of these students (38 of 42) considered it very high and high necessary to work with the resources of the smartphone. Two of professors described the quality of the offered method was moderate and two others described feebly. All of them believed the using of laptop and smartphones applications more useful than other methods. The results of need assessment of students and professors described in Table 1 and 2, respectively.

\section{The results of survey}

Sixty-five percent of students had both laptop and smartphones while $20 \%$ had a smartphone and $7 \%$ of them just had a laptop and had no smartphone. One of the students who participated in the class did not bring any necessary training devices. The results of students' satisfaction of group II described in Table 3. At the end session, $48 \%$ of students of the interactive clerkship described that all sessions were useful and valuable, while only 3\% reported that the first session of this class was the most useful session. The third session of class (using the internet sites) was the most useful session from the viewpoint of $24 \%$ of participants. Eighty-four percent of students expressed that the quality of wireless internet (internet speed and continuity of the network connection) was low and very low for performing the classes.

The results of the survey showed that interactive workshop of drug information resources (in class and at the faculty of Pharmacy) has been high and very high helpful for $65 \%$ of students. Other $35 \%$ of students assessed the presented workshop moderate effective.

\section{The results of knowledge and skills assessing}

The result of Pearson correlation test of data related to knowledge and skill assessing of group II were reported 0.69 and 0.81 , respectively. The results of the knowledge test and OSCE skill exam scores for two groups illustrated in Table 4.

Paired t-tests between the scores of the first group and the second group students for knowledge assessing showed a significant difference between mean scores of students with P-value $<0.01$. In addition, there were significant differences between OSCE exam scores of

\begin{tabular}{|c|c|c|c|c|c|}
\hline Questions & Very Low & Low & Moderate & High & $\begin{array}{l}\text { Very } \\
\text { High }\end{array}$ \\
\hline $\begin{array}{l}\text { 1) How much drug information resources workshop with the lecture } \\
\text { presented will resolve students' practical needs? }\end{array}$ & $56 \%$ & $22 \%$ & $18 \%$ & $4 \%$ & \\
\hline $\begin{array}{l}\text { 2) How much drug information resources workshop with the lecture } \\
\text { presented will produce the necessary skills to use drug information } \\
\text { resources? }\end{array}$ & $69 \%$ & $26.2 \%$ & $4.8 \%$ & $38 \%$ & $30 \%$ \\
\hline $\begin{array}{l}\text { 3) Drug information workshop with the smartphone to what extent was } \\
\text { necessitate for organizing this workshop? }\end{array}$ & & $4.8 \%$ & $4.8 \%$ & $19 \%$ & $71.4 \%$ \\
\hline $\begin{array}{l}\text { 4) Do you think you need more training to answer the drug information } \\
\text { questions? }\end{array}$ & $33.5 \%$ & $43 \%$ & $14 \%$ & $9.5 \%$ & \\
\hline
\end{tabular}




\begin{tabular}{|c|c|c|c|c|c|}
\hline Questions & Very Low & Low & Moderate & High & $\begin{array}{l}\text { Very } \\
\text { High }\end{array}$ \\
\hline $\begin{array}{l}\text { 1) Are necessary interactive and practical educations of drug information } \\
\text { resources for students? }\end{array}$ & & & & & $100 \%$ \\
\hline $\begin{array}{l}\text { 2) How much the quality of traditional method was appropriate for } \\
\text { training to the students? }\end{array}$ & & $50 \%$ & $50 \%$ & & \\
\hline $\begin{array}{l}\text { 3) Were the using of laptop and smartphones applications more useful } \\
\text { than other methods? }\end{array}$ & & & & & $100 \%$ \\
\hline
\end{tabular}

\begin{tabular}{|c|c|c|c|c|c|}
\hline Questions & Very Low & Low & Moderate & High & $\begin{array}{l}\text { Very } \\
\text { High }\end{array}$ \\
\hline $\begin{array}{l}\text { 1) How much drug information resources workshop with the presented } \\
\text { method (in class at the pharmacy faculty) was useful to you? }\end{array}$ & & & $35 \%$ & $45 \%$ & $20 \%$ \\
\hline $\begin{array}{l}\text { 2) Drug information workshop with a personal computer to what extent was } \\
\text { appropriate for organizing this workshop? }\end{array}$ & & $2 \%$ & $30 \%$ & $38 \%$ & $30 \%$ \\
\hline $\begin{array}{l}\text { 3) How much the quality of wireless internet (internet speed and continuity } \\
\text { of the network connection) was appropriate to present the workshop? }\end{array}$ & $50 \%$ & $40 \%$ & $8 \%$ & $2 \%$ & \\
\hline 4) How much of the data obtained from the workshop was new for you? & & & $20 \%$ & $60 \%$ & $20 \%$ \\
\hline $\begin{array}{l}\text { 5) How do you evaluate the appropriateness of the quality of information } \\
\text { derived from drug information resources workshop? }\end{array}$ & & $2 \%$ & $25 \%$ & $50 \%$ & $23 \%$ \\
\hline $\begin{array}{l}\text { 6) How much you recommend to other pharmacy students to participate in } \\
\text { drug information resources workshop? }\end{array}$ & & & $2 \%$ & $45 \%$ & $53 \%$ \\
\hline $\begin{array}{l}\text { 7) To what extent your expectations have been met from drug information } \\
\text { resources workshop? }\end{array}$ & & $2 \%$ & $45 \%$ & $30 \%$ & $23 \%$ \\
\hline 8) How do you evaluate the quality of the workshop? & & $2 \%$ & $36 \%$ & $50 \%$ & $12 \%$ \\
\hline
\end{tabular}

\begin{tabular}{|c|c|}
\hline \multicolumn{2}{|c|}{ Table 4: The mean and standard deviation of } \\
students' scores of knowledge test and OSCE skill \\
exam for two groups.
\end{tabular}

students in the first group with respect to prior clerkship course ( $\mathrm{p}$-value $<0.05)$.

\section{DISCUSSION}

Medical students, like other students, need updated and efficient educational methods that lead to improvement of students' skills. It is expected that new teaching methods are coordinated with rapid advances in presented science and new technologies, and lead to the further ability of students to use these technologies and development of self-directed learning skills. ${ }^{13}$

In recent years, the role of pharmacists grew to provide pharmaceutical care services including problem-solving, critical thinking, and patient communication, therefore, the students need to develop the ability to work effectively with patients and also self-directed learning skills. ${ }^{14}$ To reach this goal, the curriculum of pharmacy education should revise to contain new training methods which lead to independence in learning and continuing learning after graduated. ${ }^{4,5}$

To review of the effectiveness of new teaching methods, Monaghi et al. conducted a study and the results showed numerous advantages of using problem-based learning methods and interactive clerkship. Some of these advantages are increasing the internal motivation of students, enhancing the quality of teaching, increasing satisfaction and ability to answer the inference questions (4). Although further studies are required to evaluate the effectiveness of these teaching methods.

Even though several research studies mentioned the positive aspect of using new teaching methods, unfortunately, these positive results have not been applied in the practice (4). It seems that the teaching approach has not changed based on the evidence and the most common method of teaching in medical universities is still a traditional learning lecture-based program. One of the disadvantages of lecture-based teaching methods is the fundamental space between learning, knowledge, and acquisition of skills. ${ }^{15}$

Drug information is one of essential and applied science for pharmacy students which proper, efficient 
and up-to-date training of it can play a fundamental role in the professional performance of pharmacists to provide pharmaceutical services. Our study was first performed in the Faculty of Pharmacy to increase the skills of using drug information resources. The presented method leads to greater satisfaction. It also seems that using these training methods increased students' knowledge and skill based on the scores obtained in the written and OSCE exams compared with the prior group.

The incorporation of newly available technologies in all areas such as personal computer or laptop and smartphones in the educational program is another benefit of this training method. Training of the using of the available educational facilities leads to independence in learning and continuing learning after graduation. ${ }^{4,5,16} \mathrm{It}$ is essential to mention that in this study, students of two semesters and two different entries participated as two comparing groups. The limitation of this study is the less number of samples.

One of the challenges and constraints in this training program was the poor quality of the wireless Internet. The appropriate internet speed for a large number of students to access web resources and online programs is the essential requirements for presenting this workshop. The other limitation is that the computers and smartphones are not affordable for all students, while, the results of our investigation have shown that only one student had no access to these electronic devices.

Considering the availability of personal computers or laptops, smartphones, and Wi-Fi or $3 \mathrm{G}$ internet for the most of the students, this training program can be extended and implemented in most universities in the country, especially in clerkship courses and in the fields of the training drug information resources. In addition, this learning method can be used in other subjects of clerkship courses which require simultaneous knowledge and skill of students.

\section{CONCLUSION}

Nowadays, the providing pharmaceutical services are one of the important roles of the pharmacist. Therefore, revising of the education curriculum is necessary for the training of pharmacy students with new learning methods that lead to improving the quality of training, independence in learning and continuing learning after graduated. In this study, the interactive workshop of drug information resources in clerkship course of the hospital by using of laptop and smartphones of students lead to increase students' knowledge and skill. Then, it could be an appropriate method to improve the quality of education.

\section{CONFLICT OF INTEREST}

Low quality of wireless internet in faculty of pharmacy Inaccessibility of all students to Personal Computers and Smartphones

\section{REFERENCES}

1. Williams K, Hagemann TM, Schaeffer S. Use of electronic learning modules for teaching pharmacy and nursing staff: How to locate and utilize drug information sources in a poison control center. Currents in Pharmacy Teaching and Learning. 2013;5(1):39-43.

2. Rosenberg JM, Koumis T, Nathan JP, Cicero LA, Mcguire H. Current status of pharmacist-operated drug information centers in the United States. American Journal of Health. 2004;61(19):2023-32.

3. Fry $\mathrm{H}$, Ketteridge $\mathrm{S}$, Marshall $\mathrm{S}$. A handbook for teaching and learning in higher education: Enhancing academic practice: Routledge. 2008.

4. Karimi Monaghi HAR, Mostafa\%A Bakhshi, Mahmoud. Do the New Methods of Teaching in Medical Education have Adequate Efficacy?: A Systematic Review. Strides in Development of Medical Education. 2013;10(2):271-80.

5. Nandi PL, Chan JN, Chan CP, Chan P, Chan L. Undergraduate medical education: comparison of problem-based learning and conventional teaching. Hong Kong Medical Journal. 2000;6(3):301-6.

6. McGarr O. A review of podcasting in higher education: Its influence on the traditional lecture. Australasian Journal of Educational Technology. 2009;25(3):309-21.

7. Tormey R, Henchy D. Re-imagining the traditional lecture: An action research approach to teaching student teachers to 'do'philosophy. Teaching in Higher Education. 2008;13(3):303-14.

8. Donner RS, Bickley H. Problem-based learning in American medical education: an overview. Bulletin of the Medical Library association. 1993;81(3):294.

9. HE, M A, AA. Education learining in medical education. SID. 2009;33(2):102-11.

10. Greenhalgh T. Computer assisted learning in undergraduate medical education. BMJ (Clinical research ed). 2001;322(7277):40-4.

11. Hariri FZ, Moghaddam-Banaem L, Bazi SS, Malehi AS, Montazeri A. The Iranian version of the Premenstrual Symptoms Screening Tool (PSST): a validation study. Arch Womens Ment Health. 2013;16(6):531-7.

12. Deniz MS, Alsaffar AA. Assessing the Validity and Reliability of a Questionnaire on Dietary Fibre-related Knowledge in a Turkish Student Population. J Health Popul Nutr. 2013;31(4):497-503.

13. David TJ, Dolmans D, Patel L, Van der Vleuten C. Problem-based learning as an alternative to lecture-based continuing medical education. Journal of the Royal Society of Medicine. 1998;91(12):626-30.

14. Cisneros RM, Salisbury-Glennon JD, Anderson-Harper HM. Status of problem-based learning research in pharmacy education: a call for future research. American Journal of Pharmaceutical Education. 2002;66(1):19.

15. Smits PB, D de Buisonjé C, Verbeek JH, van Dijk FJ, Metz JC, Cate OJt. Problem-based learning versus lecture-based learning in postgraduate medical education. Scandinavian journal of work, environment and health. 2003:280-7.

16. Lee WR. Computer-based learning in medical education: a critical view. Journal of the American College of Radiology. 2006;3(10):793-8. 


\section{PICTORIAL ABSTRACT}

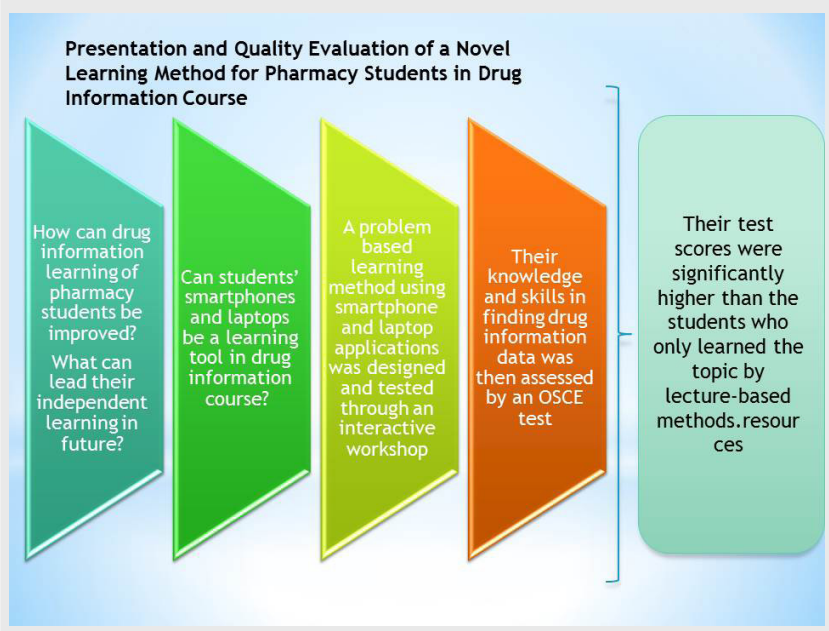

\section{SUMMARY}

- Improving the quality of training and delivery of drug information resources course was the ultimate goal of this study. An interactive workshop based on using laptops and smartphones was designed by clinical pharmacy department faculty members for pharmacy students who had the clerkship courses. Their knowledge and skills in finding drug information data was then assessed by an OSCE test. Their test scores were significantly higher than the students who only learned the topic by lecture-based methods.

\section{About Authors}

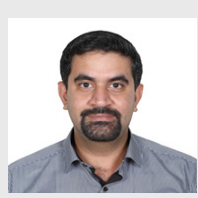

Kaveh Eslami became a board certified clinical pharmacist at the age of 29 years (2010) and completed his PhD thesis two years later, from Tehran University of Medical Sciences. He is an assistant professor in clinical pharmacy department and the head of Education Development Center at Ahvaz Jundishapur University of Medical Sciences. He has published more than 25 papers in different journals and several books in Farsi.

Leila Kouti, board certified clinical pharmacist and assistant professor in clinical pharmacy department at Ahvaz Jundishapur University of Medical Sciences, head of clinical pharmacy department.

Maryam Aghakouchakzadeh, PharmD and Clinical Pharmacy resident at Tehran University of Medical Sciences.

Mandana Izadpanah, board certified clinical pharmacist and assistant professor in clinical pharmacy department at Ahvaz Jundishapur University of Medical Sciences, head of education development organization at school of pharmacy.

Cite this article: Eslami K, Kouti L, Aghakouchakzadeh M, Khezrian M, Izadpanah M. Presentation and Quality Evaluation of a Novel Learning Method for Pharmacy Students in Drug Information Course. Indian J of Pharmaceutical Education and Research. 2018;52(4):575-80. 